\title{
Introduction to Critical Training Topics Series II: Meeting the Diverse Needs of a Changing Nation
}

\author{
Joel Bocanegra ${ }^{1} \cdot$ Gregory Callan $^{2}$ \\ Published online: 18 February 2022 \\ (c) The Author(s), under exclusive licence to California Association of School Psychologists 2022
}

Recently, we published part one of our two-part critical training special issue series (Bocanegra, 2021). Part one addressed the needs of minoritized populations and international scholarship. This second installment presents critical training topics related to school psychology's shortages crisis and innovative training practices.

\section{Shortages Crisis}

The shortages crisis is a pressing issue affecting the profession of school psychology. It has been cited as one of National Association of School Psychologists' (NASP) strategic goals (NASP, 2017). Understanding the impact of school psychology's shortage crisis and remediation efforts is important due to its potential impact on service delivery, especially in rural communities (NASP, 2020a; NASP, 2021). Many potential causes of the shortages and suggestions to remediate have been posited including increased exposure to the field (Bocanegra et al., 2015) and the creation of more training programs (Marrs et al., 2020). Furthermore, scholars have called for further research into this topic (Bocanegra et al., 2019). Gischlar (2021, in this issue) surveyed undergraduate psychology majors' preferences and found that students with increased exposure to school psychology within their undergraduate coursework reported greater interests in pursuing school psychology. The authors also found differences by racial and ethnic minoritized identity for the exposure variable but not for interest. Their findings largely mirrored previous research (e.g., Bocanegra et al., 2016) and highlight the importance of early exposure to the field and the creation and/or refinement of workforce pipelines.

\footnotetext{
$\triangle$ Joel Bocanegra

bocajoel@isu.edu

Idaho State University, Pocatello, USA

2 Utah State University, Logan, USA
}

Morrison et al., (2020, in this issue) presents a workforce pipeline analysis. A workforce pipeline analysis is a datadriven approach that allows for better understanding of personnel supply and demand issues and potential factors attributing to these issues, which can be used to identify potential areas of improvements (American Psychological Association, 2018; Morrison et al., 2020). Morrison and colleagues argue that conducting school psychology workforce pipeline analysis is important in order identify and strengthen school psychology career pipeline and, in turn, increase the number of school psychologists in the field. They identified a potential disparity within their state's workforce pipeline in regard to minoritized populations.

However, several others have posited specific initiatives in attempts to ameliorate the school psychology shortages especially within hard hit rural areas. Many of these initiatives have been made possible through the expanding use of technology. For example, Schmitz et al., (2021, in this issue) advocate for the use of a grow-your-own respecialization model in order to train practitioners within rural communities. Within their article, they outlined their own efforts in implementing a grow-your-own model, in addition to potential challenges and opportunities. Similarly, McCleary et al., (2020, in this issue) advocate for the use of distance education training programs within rural settings. They present an overview of existing distance education research and describe the history of one program's attempts to implement a distance education school psychology training program. The authors identify possible solutions to common challenges.

With the potential increased use of technology mediated instruction, it is important that researchers elucidate upon potential impact of different instructional delivery methods on graduate students' learning outcomes. Thus, Ball et al., (2020, in this issue) compared the effectiveness of campus instruction and distance-based instruction. They measured outcome variables such as GPA, Praxis-II school psychology exam scores, specialist projects, student 
retention, time to completion, and employment. The authors reported a significant increase for distance learning students in the areas of need of academic remediation plans, student withdrawal from program, and time to program completion. The authors discuss the challenges and benefits of blended delivery and implications for school psychology training.

The shortages crisis may also negatively impact school psychologists' ability to implement more comprehensive school psychology service delivery models (NASP, 2020a). For example, NASP has highlighted the importance of school-based family engagement initiatives in benefiting the education and mental health of K-12th grade students within their professional standards (NASP, 2020b). Hendricker et al., (2021, in this issue) identify the shortages crisis as a potential barrier to the implementation of such programs. In their study, they found a negative relationship between the number of schools served by a school psychologist and the availability of family focused school-based initiatives. They also found that personnel type (e.g., social worker, counselor, school psychologist) implementing family-based initiatives was impacted by the number of schools served by the school psychologist. Unfortunately, the shortages crisis is a complex phenomenon that is not projected to subside in the near future (Castillo et al., 2014) and is impacted by availability of training programs, recruitment, retention, and attrition, among others (Gadke et al., 2021).

Due to the role that attrition may play in exacerbating professional shortages, Daly and Gardner (2020, in this issue) presented a case study exploring the benefits of teaching self-care to school psychology graduate students. They argue that since school psychologists tend to experience high levels of job burnout, it is important for school psychology faculty to both model and instruct their students on self-care. The authors outline their program's attempt to teach students self-care and qualitative results from their self-study are presented. For example, participants reported an increase of self-care behaviors.

In addition, the shortages crisis, COVID-19 pandemic, and increased internet connectiveness have also brought forth the proliferation of remotely administered cognitive assessments. However, very little research has examined the training implications for the use of such technology. Hence, Corcoran (2021, in this issue) compared administration errors for traditional and digital formats of a cognitive assessment after course instruction regarding their administration. Overall, the authors found significantly more errors for the traditional compared to digital format. However, digital format still contained errors, especially in areas requiring more complex or nuanced scoring. Data regarding participants' perception regarding their use of the traditional versus digital formats are presented and implications are discussed.

\section{Innovative Training Practices}

As we attempt to meet the diverse needs of a rapidly changing nation and practice landscape, it is important that trainers and scholars actively communicate with practitioners regarding the competencies of school psychology trainees and the needs of the field. In order to better understand supervisors' perspectives of trainees' competencies, Ormiston et al., (2021, in this issue) created an electronic survey based on NASP's practice model. The authors present psychometric properties of their scales, study results, and the potential use and limitations of their instrument. Improved understanding of supervisors' perspectives of trainees' competencies could help trainers more effectively develop and hone their students' knowledge and skills.

Starling et al.'s (2020, in this issue) article echoes this focus on programmatic self-exploration and development while discussing the need for specialization and self-study within school psychology. The authors illustrate potential steps that could be followed by training programs to create specialties within school psychology. The authors highlight rationales and potential challenges in the creation of school psychology specialties.

This emphasis on the importance of specializations, whether during graduate training or after program completion, is potentially borne out of the acknowledgment of the various roles and benefits that school psychologists can play in positively impacting our nation's schools, students, and families. For example, Drapeau (2021, in this issue) examines the prevalence of sleep training within school psychology programs and argues for the importance of such training due to the impact that sleep issues can have on students' behavioral and academic functioning. He also presents recommendations for overcoming the identified lack of sleep training.

Similarly, Yu (2021, in this issue) examines the state of applied behavioral analysis (ABA) training within school psychology. They found that the majority of programs have few, if any, courses focused on these skills. They argue that due to the potential benefit that ABA modalities can have on K-12th students, school psychology training programs should increase their inclusion of ABA-related coursework.

Unfortunately, school psychology training programs have limited time to prepare their students to meet the diverse needs of K-12th grade students. Thus, an important avenue for specialization or new skill development will likely be post-graduation via continued education. One area that has received increased interest within education and psychology is self-regulated learning (SRL). Callan et al., (2020, in this issue) present a rationale for and specific steps needed to prepare school psychologists to support students' SRL, which is particularly important given the increased need for students to work independently and self-regulate. 
In summary, school psychology appears to be in a time of great opportunity. School psychologists may be uniquely positioned to support the rapidly evolving needs of our K-12 $2^{\text {th }}$ grade population. While the skills of school psychologists are in ever increasing demand, the shortage of school psychologists persists, likely impacting our ability to fully impact change. Although these challenges may require more time to address, it is our hope that the articles presented within this special issue will pave the way for further discussion, research, and action regarding these critical training issues.

\section{References}

American Psychological Association. (2018). A summary of psychologist workforce projections: Addressing supply and demand from 2015-2030. Washington, DC: Author.

Ball, C., McNeany, J., \& Hopple, A. (2020). Striking a balance in school psychology training: A comparison of blended delivery formats and student outcomes. Contemporary School Psychology. https://doi.org/10.1007/s40688-020-00332-7

Bocanegra, J. (2021). Introduction to critical training topics series: Meeting the needs of a diverse nation. Contemporary School Psychology, 25(3), 269-272. https://doi.org/10.1007/ s40688-021-00395-0

Bocanegra, J. O., Gubi, A. A., Callan, G. L., Grapin, S. L., \& McCall, J. (2019). A Lack of exposure to school psychology within undergraduate psychology coursework. Teaching of Psychology. $10.1177 \% 2$ F0098628319848876

Bocanegra, J. O., Gubi, A. A., \& Cappaert, K. J. (2016). Investigation of social cognitive career theory for minority recruitment in school psychology. School Psychology Quarterly, 31, 241-255. https://doi.org/10.1037/spq0000142

Bocanegra, J. O., Gubi, A., Fan, C., \& Hansmann, P. (2015). Undergraduate psychology students' knowledge and exposure to school psychology: Suggestions for minority recruitment. Contemporary School Psychology, 19, 12-20. https://doi.org/10.1007/ s40688-015-0046-x

Callan, G., Yang, NJ., Zhang, Y. Sciuchetti, M. (2020). Narrowing the research to practice gap: A primer to self-regulated learning application in school psychology. Contemporary School Psychology. https://doi.org/10.1007/s40688-020-00323-8

Castillo, J.M., Curtis, M.J. \& Tan, S.Y. (2014). Personnel needs in school psychology: A 10-year follow-up study on predicted personnel shortages. Psychology in the Schools. 51, 832-849. https:// doi.org/10.1002/pits.21786

Corcoran, S. (2021). Q-interactive: Training implications for accuracy and technology integration. Contemporary School Psychology. https://doi.org/10.1007/s40688-021-00368-3

Daly, B. \& Gardner, R. (2020). A case study exploration into the benefits of teaching self-care to school psychology graduate students. Contemporary School Psychology. https://doi.org/10.1007/ s40688-020-00328-3

Drapeau, C. (2021). Lost sleep: The lack of sleep education and training in school psychology. Contemporary School Psychology. https://doi.org/10.1007/s40688-021-00355-8

Gadke, D. L., Valley-Gray, S., \& Rossen, E. (2021). NASP report of graduate education in school psychology: 2018-2019 [Research report]. Bethesda, MD: National Association of School Psychologists.

Gischlar, K. (2021). Why (not) school psychology?: A survey of undergraduate psychology majors' preferences. Contemporary School Psychology. https://doi.org/10.1007/s40688-020-00350-5
Hendricker, E., Bender, S., \& Ouye, J. (2021). The school psychology shortage and its impact on family-based programming. Contemporary School Psychology. https://doi.org/10.1007/ s40688-021-00354-9

Marrs, H., Ruby, S., \& Chaffin, J. (2020). School psychology training program capacity in the Pacific Northwest. School Psychology Training and Pedagogy, 37, 20-28.

McCleary, D., Clark, F., Dawes, J., Flowers, J., \& Ellis-Hervey, N. (2020). Going digital to address the school psychologist shortage. Contemporary School Psychology. https://doi.org/10.1007/ s40688-020-00327-4

Morrison, J., Davies, S., \& Noltemeyer, A. (2020). An analysis of the workforce pipeline in school psychology. Contemporary School Psychology. https://doi.org/10.1007/s40688-020-00319-

National Association of School Psychologists. (2017). National Association of School Psychologists strategic plan: 2017-2022. Bethesda, MD: Author. Retrieved from https://www.nasponline.org/utility/ about-nasp/vision-core-purpose-core-values-and-strategic-goals

National Association of School Psychologists. (2020a). Addressing shortages in school psychology: Resource guide. Retrieved from https://www.nasponline.org/shortages

National Association of School Psychologists. (2020b). The professional standards of the National Association of School Psychologists. Bethesda, MD: Author.

National Association of School Psychologists. (2021). Shortages in school psychology: Challenges to meeting the growing needs of U.S. students and schools [Research summary].

Ormiston, H., Dixon, A. \& Barnett, A. (2021). School psychology supervisors' perceptions of specialist-level training: An exploratory study. Contemporary School Psychology. https://doi.org/10. 1007/s40688-021-00363-8

Schmitz, S., Clopton, K., Skaar, N., Dredge, S., \& VanHorn, D. (2021). Increasing school-based mental health services with a "grow your own" school psychology program. Contemporary School Psychology. https://doi.org/10.1007/s40688-020-00348-z

Starling, N., Elias, E., \& Coleman, M. (2020). Further exploration in the specialization of school psychology: Graduate training and self-study. Contemporary School Psychology. https://doi.org/10. 1007/s40688-020-00325-6

Yu, R. (2021). Behavior analytic skills training in school psychology programs. Contemporary School Psychology. https://doi.org/10. 1007/s40688-021-00369-2

Publisher's Note Springer Nature remains neutral with regard to jurisdictional claims in published maps and institutional affiliations.

Joel Bocanegra, Ph.D., NCSP Dr. Bocanegra graduated with a PhD in educational psychology with a concentration in school psychology from the University of Wisconsin-Milwaukee. He is a licensed psychologist and school psychologist. He is an Associate Professor and school psychology training director in the Department of School Psychology and Educational Leadership at Idaho State University. He teaches Clinical School Psychology, Developmental Psychopathology, Multicultural Issues in School Psychology, and Cognitive Behavioral Interventions courses, among others. He is a noted scholar on multicultural issues, diversity recruitment, and professional practice issues. He co-chaired a national recruitment committee, sits on various editorial boards, and works extensively with minority youth and underserved populations.

Greg Callan is an assistant professor of psychology and a member of the core faculty of the school psychology program at Utah State University. Dr. Callan's primary area of research is self-regulated learning assessments and interventions. 